\title{
Comparison of Vitamin D Levels in Naive, Treated, and Inactive Carriers with Chronic Hepatitis B Virus
}

\author{
Shahnaz Sali, Soheil Tavakolpour* and Baharan Farkhondemehr \\ Infectious Diseases and Tropical Medicine Research Center, Shahid Beheshti University of Medical Sciences, Tehran, Iran
}

\begin{abstract}
Background and Aims: During recent years, the relationship between vitamin D levels and chronic hepatitis B (CHB) infection has attracted many researchers' attention. However, the results relating to the association of vitamin $D$ levels and HBV infection have been conflicting and there remains a lack of knowledge about the effects of antiviral treatments on vitamin D level. Methods: Eighty-four patients with $\mathrm{CHB}$ were assessed and divided into three groups: inactive carriers ( $n=28)$, treated $(n=34)$, and new (treatment-naïve) cases $(n=22)$. Thirty-two healthy controls (HCs) were included to enable comparison with the CHB groups. The levels of vitamin D3 were measured and statistically compared among the various groups. Results: Male subjects had higher levels of vitamin D3 (41.25 vs 28.85, $p<0.01$ ). No association was found among any of the groups when compared with the HC group. Despite the significant association, the HCs demonstrated a higher level of vitamin D3, which was lower in the treated group, the inactive carrier group, and the new cases group (new case [29.82] < inactive carrier [32.91] < treated [39.56] < control [44.88]). The HBV DNA levels were not associated with vitamin D3 levels in the inactive carriers $(p=0.171)$, the treated groups $(p=0.192)$, and the new cases $(p=0.369)$. Moreover, the alanine transaminase and aspartate transaminase levels were not associated with vitamin D3 levels for any of the HBV-infected groups. Conclusions: Vitamin D3 contributes to the clinical statues of CHB patients. There is also a possible correlation between clinically healthy CHB patients and vitamin D3 level.

(C) 2016 The Second Affiliated Hospital of Chongqing Medical University. Published by XIA \& HE Publishing Inc. All rights reserved.
\end{abstract}

\section{Introduction}

Recently, 1,25-dihydroxyvitamin D3 (1,25(OH)2D3), the active form of vitamin $D$, has been recognized as a new player in modulation of the immune system. Despite its critical role in the immune system, however, impaired vitamin D3 status has been reported amongst various populations. ${ }^{1}$ As an immunomodulatory factor, vitamin D3 affects various types of cells involved in a plethora of immune responses, including monocytes, macrophages, dendritic cells and both the $\mathrm{T}$ and $\mathrm{B}$ lymphocytes. ${ }^{2}$ Indeed, a critical role has been described for vitamin D3 in different autoimmune diseases, such as multiple sclerosis, rheumatoid arthritis, psoriasis and autoimmune blistering diseases. ${ }^{3-7}$ However, there is a lack of in-depth research on the roles of vitamin D3 in viral hepatitis. During recent years, some studies have focused on the effect of vitamin D3 in hepatitis C virus (HCV) infection, as well as in infection with hepatitis B virus (HBV). Since the vitamin $D$ receptor (VDR) is necessary for the effects of vitamin D3, it is expected that polymorphisms of the VDR genetic sequences may also contribute to the pathogenesis of several diseases. ${ }^{8}$ Since VDR is expressed on both Tand B cells, ${ }^{9}$ it is especially likely that the function of these cells could be influenced by vitamin D3 level.

Multiple studies have shown that vitamin D3 level is significantly correlated with the suppressor function of T cells. ${ }^{10}$ Several in vitro and in vivo studies of murine models, as well as patient-based clinical studies, have indicated involvement of the vitamin D signaling pathway (both vitamin D3 level and VDR status) related to the regulatory T cells (Tregs) and their function. It has been concluded that vitamin D3 acts on antigen presenting cells (APCs) and T cells to induce peripheral tolerance via promotion of Tregs. ${ }^{11}$ Prietl et al. ${ }^{12}$ demonstrated that vitamin D3 supplementation is associated with a significant increase in the Tregs population. Thus, vitamin D could inhibit Thelper (Th) 1 cells and Th17-associated cytokines, while promoting Th2 cells and also expanding the Tregs. ${ }^{13-16}$

Although, in HBV infection immune responses are not the main player; nonetheless, these could lead to development of other diseases, to seroclearance or chronicity. Additionally, it seems that immune cell differentiation and activation are strongly influenced by the disease course. It was recently hypothesized that both Tregs and regulatory B cells (Bregs) may function as a barrier in HBV seroclearance. ${ }^{17}$ However, the presence of Tregs are essential to prevent HBV flare. ${ }^{18}$ All these reported data are in line with the purported crucial role of Tregs in HBV infection.

Investigation of the beneficial role of vitamin $D$ in $\mathrm{HBV}$ infection was first reported by Luong and Nguyen, ${ }^{19}$ and several other studies followed thereafter. Some of the subsequent 
studies have showed a lower level of vitamin D3 in patients with chronic HBV (CHB), and these have mainly been presented during the most recent years. Indeed, some authors have suggested that the decreased level of this vitamin may be the cause of abnormal findings on liver function tests (LFTs) and/ or the characteristic elevation in viral load observed in patients with $\mathrm{CHB}$. However, other authors have reported not finding any correlation between viral load and vitamin D3 level in HBVinfected patients. ${ }^{20}$

Due to the existence of conflicting results from the different studies, we sought to perform a study in which we measured and analyzed the level of vitamin D3 in patients with three different clinical statuses of HBV infection and to compare these data with the same from selected healthy controls (HCs). Additionally, we made efforts to include some critical parameters, including levels of alanine transaminase $(A L T)$, aspartate transaminase (AST), platelet count (PLT) and HBV DNA. Recently, Mohamadkhani et al. ${ }^{21}$ showed that there is a negative correlation between vitamin D3 levels and viral load in Iranian patients, with an acceptable population $(n=173)$. Distinctively, however, we attempted to evaluate the association of plasma vitamin D3 and the different $\mathrm{CHB}$ phases amongst an Iranian population in the present study.

\section{Methods}

Eighty-four patients with $\mathrm{CHB}$ who presented to the Shahid Labafinejad Hospital in Tehran, Iran from May 2015 to February 2016 were included in the study. The patients were divided among three groups: inactive carriers $(n=28)$, treated $(n=34)$, and new (treatment-naïve) cases $(n=22)$. The exact definitions of these groups are shown in Table 1. Additionally, $32 \mathrm{HCs}$ were included to compare their vitamin D3 levels and some other factors with the three HBV-infected patient groups. The inclusion criteria used for selection of HCs are presented in Table 1 . Since the available first-line treatment for HBV patients in Iran was changed to tenofovir during the past years, individuals in the treated group only received tenofovir for at least 1 year, at a dose of $300 \mathrm{mg}$ daily. Patients with any other treatments were not included in the treated group.

Because of the influence of 25-hydroxyvitamin D3 from sunlight during different seasons, all of the samples used in
Table 1. Definition of the different groups included in this study

\begin{tabular}{|c|c|}
\hline Group & Defining characteristics \\
\hline $\begin{array}{l}\text { Inactive } \\
\text { carrier }\end{array}$ & $\begin{array}{l}\text { Negative HBeAg and positive HBeAb, } \\
\text { undetectable or low levels of HBV DNA } \\
\text { (<2000 IU/mL) by PCR-based assays, } \\
\text { repeatedly normal ALT levels, and no } \\
\text { fibrosis. }\end{array}$ \\
\hline Treated & $\begin{array}{l}\text { Receipt of anti-viral therapy (tenofovir) for at } \\
\text { least } 1 \text { year, at the dose of } 300 \text { mg daily, } \\
\text { within at least } 6 \text { months before analysis of } \\
\text { the vitamin D } 3 \text { levels, and regardless of } \\
\text { HBeAg or HBeAb status. }\end{array}$ \\
\hline New case & $\begin{array}{l}\text { Newly diagnosed patients based on } \\
\text { serological tests, HBV DNA }>2000 \mathrm{IU} / \mathrm{mL} \text {, no } \\
\text { anti-viral therapy had been initiated at the } \\
\text { time of vitamin D3 measurement. }\end{array}$ \\
\hline Control & $\begin{array}{l}\text { Healthy individuals without any viral } \\
\text { hepatitis and liver disease history, no } \\
\text { autoimmune diseases or cancer history, no } \\
\text { vitamin D3 supplementation or taking of } \\
\text { multi-vitamins during the past } 3 \text { months. }\end{array}$ \\
\hline
\end{tabular}

this study were collected during autumn and winter. In addition to the vitamin D3 levels, ALT, AST, PLT, HBV DNA and body mass index (BMI) were recorded for every individual (Table 2). In this study, HBV DNA was not necessarily measured at the time of sample analysis. In fact, the results of measured HBV DNA within the past 3 months were considered as trustworthy to include in the study.

During the patient selection for study, any patient with any other liver diseases that were not associated with HBV, such as bone disorders, autoimmune diseases, cancer, any co-infections (human immunodeficiency virus, HCV), and any patient taking vitamin D3 supplements during the past 3 months were excluded to minimize the effects of other parameters. In addition, the number of male patients enrolled in the study was considerably higher than that of female patients (63 vs 21), which was due to the general higher proportion of infected males.

Table 2. Comparison of clinical and biochemical features of HBV patients and healthy controls

\begin{tabular}{|c|c|c|c|c|c|c|}
\hline & & $\begin{array}{l}\text { Inactive carrier } \\
(n=28)\end{array}$ & $\begin{array}{l}\text { New case } \\
(n=22)\end{array}$ & $\begin{array}{l}\text { Treated } \\
(n=34)\end{array}$ & $\begin{array}{l}\text { Control } \\
(n=32)\end{array}$ & $p$ \\
\hline \multirow[t]{2}{*}{ Sex } & $F(\%)$ & $10(36)$ & $2(10)$ & $10(29)$ & $14(44)$ & 0.047 \\
\hline & $M(\%)$ & $18(64)$ & $20(90)$ & $24(71)$ & $18(56)$ & \\
\hline Age, years & & $47.9 \pm 15.41$ & $43.85 \pm 13.73$ & $44.25 \pm 11.11$ & $44.93 \pm 15.23$ & 0.713 \\
\hline ALT, IU/L & & $26.00 \pm 10.03$ & $58.95 \pm 22.01$ & $30.11 \pm 11.89$ & $26.87 \pm 12.61$ & 0 \\
\hline AST, IU/L & & $25.21 \pm 6.23$ & $49.36 \pm 15.74$ & $29.11 \pm 13.18$ & $25.67 \pm 12.92$ & 0 \\
\hline PLT, $10^{5}$ & & $2.92 \pm 0.84$ & $3.05 \pm 1.31$ & $3.08 \pm 1.05$ & $3.34 \pm 0.71$ & 0.091 \\
\hline \multirow[t]{2}{*}{ Vitamin D3, ng/mL } & $\mathrm{F}$ & $31.91 \pm 35.79$ & $10.00 \pm 7.07$ & $22.88 \pm 25.71$ & $33.14 \pm 31.08$ & 0.127 \\
\hline & M & $33.44 \pm 31.60$ & $31.80 \pm 34.47$ & $45.27 \pm 33.40$ & $53.94 \pm 34.79$ & \\
\hline BMI & & $27.57 \pm 2.99$ & $26.46 \pm 3.96$ & $27.32 \pm 4.43$ & $26.68 \pm 4.87$ & 0.796 \\
\hline Viral load, log IU/mL & & $3.69 \pm 3.46$ & $6.45 \pm 6.99$ & $3.70 \pm 4.30$ & N/A & 0 \\
\hline
\end{tabular}




\section{Laboratory tests}

Collected samples were analyzed for ALT, AST, PLT and vitamin D3 levels. ALT and AST were measured using IFCC (G.T kit; Pars Azmoon Company). PLT was measured by counting. Vitamin D3 level measurement was performed using chemiluminescence (Roche Kit; Elecsis Company). The measured vitamin D3 levels were categorized as deficient, insufficient or sufficient according to findings of less than $10 \mathrm{ng} / \mathrm{mL}$, between $10 \mathrm{ng} / \mathrm{mL}$ and $20 \mathrm{ng} / \mathrm{mL}$, and more than $20 \mathrm{ng} / \mathrm{mL}$, respectively.

\section{Statistically analysis}

SPSS version 16 (IBM Corporation, USA) was used for all statistical analyses. A $p$-value of less than 0.05 was considered to indicate statistical significant differences between groups.

\section{Results}

The levels of vitamin D3 were significantly higher in male patients than in female patients $(41.25$ vs $28.85, p<0.01)$. Comparison of the vitamin D3 levels between the three HBV-infected groups and the HCs showed no significant association. Although there was no significant association found between the vitamin D3 levels in the different groups, the mean vitamin D3 levels were different. As expected, the mean level of vitamin D3 was highest in the HCs and lowest in the new cases (new case [29.82] < inactive carrier [32.91] $<$ treated [39.56] < HCs [44.88]). Fig. 1 illustrates the mean levels of vitamin D3 in all four groups. Furthermore, no significant association was found to exist between the categorized levels of vitamin D3 (Fig. 2). Although there was no significant association between vitamin D3 levels among the different groups, the mean level of vitamin D3 in any of the three HBV-infected groups was lower than that in the HCs. It seems that treatment, which clinically improves patient status, could also elevate vitamin D3 towards a normal level. Inactive carriers, who have better clinical status compared

Vitamin D3 level

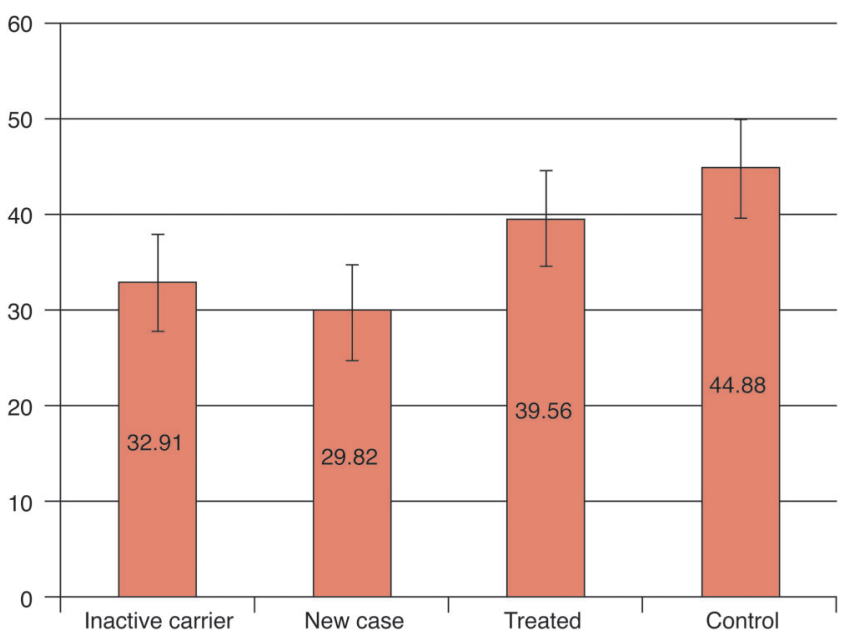

Fig. 1. Mean vitamin D3 levels of HBV-infected patients, including inactive carriers, new cases and treated patients, and healthy controls.

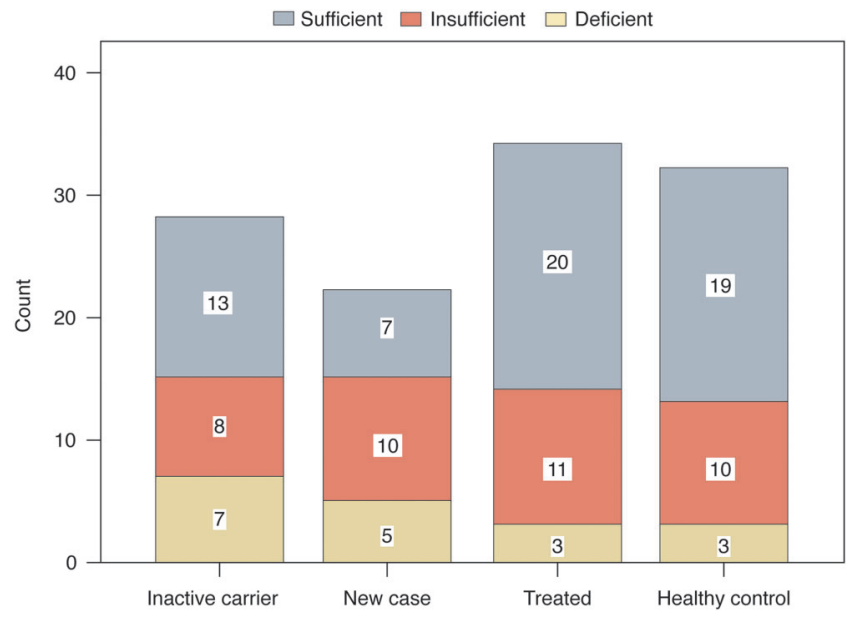

Fig. 2. Frequency of each category of vitamin D3 among HBV-infected patients, including inactive carriers, new cases and treated patients, and healthy controls.

with new cases, showed a higher mean level of vitamin D3. These results indicated a possible correlation between the clinical health status of HBV-infected patients and their vitamin D3 level.

After analyzing the HBV DNA levels and vitamin D3 levels in the three group of HBV-infected patients, no significant association was found between these two parameters, specifically for the inactive carriers $(p=0.171)$, the treated patients $(p=0.192)$ and the new cases $(p=0.369)$. Both ALT and AST levels were significantly lower in the female patients than in the male patients (ALT: 25.03 vs 37.56, $p<0.001$; AST: 23.78 vs 34.07, $p<0.004$ ). In contrast, there was no significant association between the ALT or AST levels and vitamin D3 in any of the HBV-infected groups.

\section{Discussion}

As described earlier, vitamin D3 is strongly associated with immune responses. Considering the involvement of immune responses in determination of clinical status of individuals infected with HBV, it is expected that the level of this vitamin is varied during the pathogenic course of HBV infection. Several other studies have shown a significant decline of this vitamin in CHB patients, which was not confirmed in the present study. We found a similar trend, however, but it was not significant. This finding may simply reflect the limited number of cases in each of our study groups. However, it is possible that the decreased levels of vitamin D3 detected in our CHB patients, which was similarly reported in previous studies, may not be related to immune responses directly but it could affect those responses. Generally, it is accepted that liver disease, such as HBV infection, can cause an impaired absorption of vitamin $D$, which is not directly related to the immune system. In fact, it could possibly be connected to impaired bile acid production or gut edema associated with portal hypertension. ${ }^{22}$

Due to the dependence of vitamin D3 level on sunlight, it is generally accepted that in autumn and winter, the level of vitamin D3 in plasma decreases. The level increases in spring and summer. Although vitamin D3 levels of the CHB groups and the $\mathrm{HCs}$ were all measured during the same seasons 
(autumn and winter) in this study, the overall results of measurement in the two other seasons that we did not assess may be different. Additionally, amongst the Iranian population, the level of vitamin D3 has been reported to be generally lower than the mean global value. ${ }^{23,24}$ Because our samples were taken from an Iranian population, the results may be influenced by this issue. Moreover, because the HCs were not selected according to a sex-matching approach and a higher proportion of male patients were present in the study groups (those with higher vitamin D3 level), the mean levels of vitamin D3 in the HCs may have been governed by the female patients, in contrast to the three other groups examined. Accordingly, all of these potentially confounding factors could have impacted the mean level of vitamin D3 among the $\mathrm{HCs}$ so that it was less than its true level.

Considering the fact that vitamin D3 causes inhibition of Th1 and Th17 cells, which represent two important arms of immune responses during HBV infection, and also increases the risk of HBV flare related to promoted HBV-specific immune responses, it appears that vitamin D3 contributes to regulation of immune responses. This could lead to lower liver damage, because of declined cytotoxic and non-cytotoxic actions of CD4+ and CD8+ cell-associated cytokines. From the Th2 and Tregs promotion, which leads to decreased HBVspecific immune responses (IFN- $\gamma$ and TNF- $\alpha$ ), an elevation in viral load could occur. According to our previous studies, high levels of anti-HBV cytokines or low levels of these cytokines could lead to HBV flare and HBV reactivation, respectively. ${ }^{18,25}$ It seems that vitamin D3 contributes to prevention of HBV flare via a mechanism involving increase in Tregs population and promotion of their functions. Thus, vitamin D3 supplementation could represent a therapeutic option for $\mathrm{CHB}$ patients with HBV flare.

We believe that vitamin D3 has other effects on the HBVspecific immune responses, which have not yet been recognized. Based on our current knowledge about the effects of vitamin D3 on T cell function and the critical roles of T cells during HBV infection, an increase in vitamin D3 level is likely to help in reversing HBV flare, whilst its role in elevation in viral load was not confirmed in the current study, neither has it been confirmed by others.

\section{Conflict of interest}

None

\section{Author contributions}

Study concept and design (SS, ST), acquisition of data (SS, $\mathrm{BF}$ ), analysis and interpretation of data (ST), drafting of the manuscript (ST, BF), critical revision of the manuscript for important intellectual content (SS), administrative, technical, and material support (ST), study supervision (SS).

\section{References}

[1] Hewison M. An update on vitamin D and human immunity. Clin Endocrinol (Oxf) 2012;76:315-325. doi: 10.1111/j.1365-2265.2011.04261.x.
[2] Baeke F, Takiishi T, Korf H, Gysemans C, Mathieu C. Vitamin D: modulator of the immune system. Curr Opin Pharmacol 2010;10:482-496. doi: 10. 1016/j.coph.2010.04.001.

[3] Ascherio A, Munger KL, Simon KC. Vitamin D and multiple sclerosis. Lancet Neurol 2010;9:599-612. doi: 10.1016/S1474-4422(10)70086-7.

[4] Kostoglou-Athanassiou I, Athanassiou P, Lyraki A, Raftakis I, Antoniadis C. Vitamin D and rheumatoid arthritis. Ther Adv Endocrinol Metab 2012;3: 181-187. doi: $10.1177 / 2042018812471070$.

[5] Soleymani T, Hung T, Soung J. The role of vitamin $D$ in psoriasis: a review. Int J Dermatol 2015;54:383-392. doi: 10.1111/ijd.12790.

[6] Zarei M, Javanbakht MH, Chams-Davatchi C, Daneshpazhooh M, Eshraghian MR, DE-Rakhshanian $\mathrm{H}$, et al. Evaluation of vitamin $\mathrm{D}$ status in newly diagnosed pemphigus vulgaris patients. Iran J Public Health 2014;43: 1544-1549.

[7] Marzano AV, Trevisan V, Eller-Vainicher C, Cairoli E, Marchese L, Morelli V, et al. Evidence for vitamin $D$ deficiency and increased prevalence of fractures in autoimmune bullous skin diseases. Br J Dermatol 2012;167:688-691. doi: 10.1111/j.1365-2133.2012.10982.x.

[8] Valdivielso JM, Fernandez E. Vitamin D receptor polymorphisms and diseases. Clin Chim Acta 2006;371:1-12. doi: 10.1016/j.cca.2006.02.016.

[9] Provvedini DM, Tsoukas CD, Deftos LJ, Manolagas SC. 1,25-dihydroxyvitamin D3 receptors in human leukocytes. Science 1983;221:1181-1183.

[10] Smolders J, Thewissen M, Peelen E, Menheere P, Tervaert JW, Damoiseaux J, et al. Vitamin D status is positively correlated with regulatory $T$ cell function in patients with multiple sclerosis. PLoS One 2009;4:e6635. doi: 10.1371/ journal.pone.0006635.

[11] Chambers ES, Hawrylowicz CM. The impact of vitamin D on regulatory Tcells. Curr Allergy Asthma Rep 2011;11:29-36. doi: 10.1007/s11882-010-0161-8.

[12] Prietl B, Pilz S, Wolf M, Tomaschitz A, Obermayer-Pietsch B, Graninger W, et al. Vitamin $D$ supplementation and regulatory $T$ cells in apparently healthy subjects: vitamin D treatment for autoimmune diseases? Isr Med Assoc J 2010;12:136-139.

[13] Lemire JM, Archer DC, Beck L, Spiegelberg HL. Immunosuppressive actions of 1,25-dihydroxyvitamin D3: preferential inhibition of Th1 functions. J Nutr 1995; 125:1704S-1708S.

[14] Boonstra A, Barrat FJ, Crain C, Heath VL, Savelkoul HF, O'Garra A. 1alpha,25Dihydroxyvitamin d3 has a direct effect on naive CD4(+) T cells to enhance the development of Th2 cells. J Immunol 2001;167:4974-4980.

[15] Joshi S, Pantalena LC, Liu XK, Gaffen SL, Liu H, Rohowsky-Kochan C, et al. 1,25-dihydroxyvitamin $D(3)$ ameliorates Th17 autoimmunity via transcriptional modulation of interleukin-17A. Mol Cell Biol 2011;31:3653-3669. doi: 10.1128/MCB.05020-11.

[16] Ardalan MR, Maljaei H, Shoja MM, Piri AR, Khosroshahi HT, Noshad H, et al. Calcitriol started in the donor, expands the population of CD4+CD25+ T cells in renal transplant recipients. Transplant Proc 2007;39:951-953. doi: 10. 1016/j.transproceed.2007.04.012.

[17] Tavakolpour S. Inhibition of regulatory cells as a possible cure of chronically hepatitis B virus infected patients. Immunol Lett 2016;171:70-71. doi: 10. 1016/j.imlet.2015.12.007.

[18] Tavakolpour S. The new insight into management of hepatitis $B$ virus patients with flare. Immunol Lett 2016;173:77. doi: 10.1016/j.imlet.2016.02.008.

[19] Lương Kv, Nguyễn LT. Theoretical basis of a beneficial role for vitamin D in viral hepatitis. World J Gastroenterol 2012;18:5338-5350. doi: 10. 3748/wjg.v18.i38.5338.

[20] Tavakolpour S, Sali S, Gachkar L. Association of plasma levels of vitamin D with chronic hepatitis B infection. Hepat Mon 2016;16:e35525. doi: 10. 5812/hepatmon.35525.

[21] Mohamadkhani A, Bastani F, Khorrami S, Ghanbari R, Eghtesad S, Sharafkhah $M$, et al. Negative association of plasma levels of vitamin D and miR-378 with viral load in patients with chronic hepatitis B infection. Hepat Mon 2015; 15:e28315. doi: 10.5812/hepatmon.28315v2.

[22] Nair S. Vitamin d deficiency and liver disease. Gastroenterol Hepatol (N Y) 2010;6:491-493.

[23] Ebrahimi M, Khashayar P, Keshtkar A, Etemad K, Dini M, Mohammadi Z, et al. Prevalence of vitamin D deficiency among Iranian adolescents. J Pediatr Endocrinol Metab 2014;27:595-602. doi: 10.1515/jpem-2013-0428.

[24] Hovsepian S, Amini M, Aminorroaya A, Amini P, Iraj B. Prevalence of vitamin $D$ deficiency among adult population of Isfahan City, Iran. J Health Popul Nutr 2011;29:149-155.

[25] Tavakolpour S, Alavian SM, Sali S. Hepatitis B reactivation during immunosuppressive therapy or cancer chemotherapy, management, and prevention: a comprehensive review-screened. Hepat Mon 2016;16:e35810. doi: 10.5812/hepatmon.35810. 